\title{
Assessing immune response upon systemic RNA vaccination on [18F]-FDG PET/CT for COVID-19 vaccine and then for immuno-oncology?
}

\author{
Romain-David Seban ${ }^{1,2}$ (1) $\cdot$ Laurence Champion $^{1,2} \cdot$ Randy Yeh $^{3} \cdot$ Lawrence H. Schwartz $^{4} \cdot$ Laurent Dercle $^{4}$
}

Received: 3 June 2021 / Accepted: 16 June 2021 / Published online: 23 June 2021

(๖) The Author(s), under exclusive licence to Springer-Verlag GmbH Germany, part of Springer Nature 2021

Keywords RNA vaccination · [18F]-FDG PET/CT · COVID-19 · Immuno-oncology

Dear Sir,

The publication " 18 Fluorodeoxyglucose PET/CT findings in a systemic inflammatory response syndrome after COVID19 vaccine" reports the case of a 65 -year-old woman with increased glucose metabolism in lymphoid tissues diagnosed on [18F]-FDG PET/CT performed 4 days after the first dose of mRNA COVID-19 vaccine [1]. This finding highlights the phenomenon of reactive adenopathy on imaging examinations following vaccination and the need for increasing public awareness and guidelines for clinical practice [2].

The Lancet report also raises the potential of [18F]-FDG $\mathrm{PET} / \mathrm{CT}$ as a potent tool to assess immune response after mRNA vaccinations. There is now an abundance of evidence demonstrating that immune response increases glucose metabolism in lymphoid organs, which are critical modulators of T-cell immunity [3].

The technology of mRNA vaccination offers promising prophylactic and therapeutic potentials in several medical fields including immuno-oncology [4]. Therefore, current

This article is part of the Topical Collection on Oncology General

Romain-David Seban

romain.seban@gmail.com

1 Department of Nuclear Medicine, Institut Curie, 92210 Saint-Cloud, France

2 Laboratoire D'Imagerie Translationnelle en Oncologie, Inserm, Institut Curie, 91401 Orsay, France

3 Molecular Imaging and Therapy Service, Department of Radiology, Memorial Sloan Kettering Cancer Center, New York, NY, USA

4 Department of Radiology, New York-Presbyterian Hospital, Columbia University Medical Center, New York, NY, USA oncological clinical trials should consider the potential theranostic value of [18F]-FDG PET and correlate temporal changes in glucose metabolism of lymphoid tissues with treatment outcome. For instance, a rapid and transient increase in spleen glucose metabolism after RNA cancer vaccine connotes robust immune activation and T-cell proliferation [5]. The same argument can be made for hypermetabolic draining lymph nodes, which could reflect a prominent $B$ cell germinal center activation and an effective humoral response elicited by mRNA vaccine [6].

In conclusion, while the contemporary role of [18F]FDG PET/CT is predominantly cancer imaging, there is a paradigm shift toward assessing healthy lymphoid tissues for in vivo quantification of the immune response. In the setting of RNA vaccination, this could be used as a theranostic tool for a wide range of indications in multiple therapeutic areas.

\section{Declarations}

Ethics approval This article does not contain any studies with human participants performed by any of the authors.

Consent to participate Not applicable.

Conflict of interest The authors declare no competing interests.

\section{References}

1. Steinberg J, Thomas A, Iravani A. 18F-fluorodeoxyglucose PET/ CT findings in a systemic inflammatory response syndrome after COVID-19 vaccine. Lancet. 2021;397:e9.

2. Becker AS, Perez-Johnston R, Chikarmane SA, Chen MM, El Homsi M, Feigin KN, et al. Multidisciplinary recommendations regarding post-vaccine adenopathy and radiologic imaging: 
radiology scientific expert panel. Radiology. 2021;210436. https:// doi.org/10.1148/radiol.2021210436.

3. Cafri G, Gartner JJ, Zaks T, Hopson K, Levin N, Paria BC, et al. mRNA vaccine-induced neoantigen-specific $\mathrm{T}$ cell immunity in patients with gastrointestinal cancer. J Clin Invest. 2020;130:5976-88.

4. Miao L, Zhang Y, Huang L. mRNA vaccine for cancer immunotherapy. Mol Cancer. 2021;20:41.

5. Pektor S, Hilscher L, Walzer KC, Miederer I, Bausbacher N, Loquai $\mathrm{C}$, et al. In vivo imaging of the immune response upon systemic RNA cancer vaccination by FDG-PET. EJNMMI Res. 2018;8:80

6. Cohen D, Hazut Krauthammer S, Cohen YC, Perry C, Avivi I, Herishanu Y, et al. Correlation between BNT162b2 mRNA
Covid-19 vaccine-associated hypermetabolic lymphadenopathy and humoral immunity in patients with hematologic malignancy. Eur J Nucl Med Mol Imaging [Internet]. 2021 [cited 2021 Jun 3]; Available from: https://link.springer.com/10.1007/ s00259-021-05389-x.

Publisher's note Springer Nature remains neutral with regard to jurisdictional claims in published maps and institutional affiliations. 